\title{
CLINICO-PATHOLOGICAL STUDY OF CUTANEOUS TUBERCULOSIS IN A TERTIARY CARE HOSPITAL, RURAL PUDUCHERRY
}

\author{
Rathna Shivanna1, Govindaraj Thimmarayan², Venkatraman Janarthanam³, Kandibanda Sai Sri Ram Rao ${ }^{4}$ \\ ${ }^{1}$ Associate Professor, Department of Pathology, Sri Venkateshwaraa Medical College and Research Centre, Puducherry. \\ ${ }^{2}$ Associate Professor, Department of Pathology, Sri Venkateshwaraa Medical College and Research Centre, Puducherry. \\ ${ }_{3}^{3}$ Assistant Professor, Department of Pathology, Mahatma Gandhi Medical College and Research Institute, Puducherry. \\ 4 Postgraduate Student, Department of Pathology, Sri Manakula Vinayagar Medical College and Hospital, Puducherry.
}

\section{ABSTRACT}

\section{BACKGROUND}

Skin is one of the frequently affected organs among the extrapulmonary tuberculosis accounting for $1.5 \%$ of all cases. Cutaneous tuberculosis manifests with varied clinical presentation determined by the route of entry of infection as well as status of the immunity of the patient. Hence, biopsy is imperative for histopathological study in cases of atypical clinical presentation.

The aim of the present study is to study the clinical and histopathological features of cutaneous tuberculosis.

\section{MATERIALS AND METHODS}

The present retrospective study was carried out in the Department of Pathology from July 2015 to June 2016 ; 46 cases of histopathologically diagnosed cutaneous tuberculosis were included for the study.

\section{RESULTS}

The study showed slight male preponderance. The most common age group affected was between 20 and 30 years. Majority of the lesions were seen on limbs (60\%) and lupus vulgaris was the commonest variant encountered (54\%). Majority of the lesions showed well-formed epithelioid granuloma with caseous necrosis.

\section{CONCLUSION}

Due to the varied clinical presentation, the diagnosis of cutaneous tuberculosis is often difficult. Hence, both clinical and pathological parameters play a large role in the early and accurate diagnosis of cutaneous tuberculosis.

\section{KEYWORDS}

Cutaneous Tuberculosis, Granuloma, Histopathological, Lupus Vulgaris, Scrofuloderma, Tuberculosis Verrucosa Cutis, Papulonecrotic Tuberculid.

HOW TO CITE THIS ARTICLE: Shivanna R, Thimmarayan G, Janarthanam V, et al. Clinico-pathological study of cutaneous tuberculosis in a tertiary care hospital, rural Puducherry. J. Evolution Med. Dent. Sci. 2016;5(100):7381-7383, DOI: $10.14260 /$ jemds/2016/1670

\section{BACKGROUND}

Tuberculosis (TB) is a global issue, especially in developing countries like India. Extrapulmonary Tuberculosis incidence is expanding owing to multiple factors like increased virulence of the bacteria, emergence of drug-resistant strain and close association of TB with HIV. ${ }^{1}$

Among the extrapulmonary TB, skin is the frequently affected organ. Cutaneous TB presents with varied clinical features ranging from papules, nodules, ulcers and papillomatous lesions depending on the route of entry of the bacilli and immune status of the host. ${ }^{2}$ Primary infection of the skin and subcutis with tuberculosis is very rare and occurs by three routes:

1. Direct inoculation into the skin as in tuberculosis verrucosa cutis.

Financial or Other, Competing Interest: None.

Submission 24-11-2016, Peer Review 07-12-2016,

Acceptance 09-12-2016, Published 15-12-2016.

Corresponding Author:

Dr. Venkatraman Janarthanam,

Assistant Professor,

Department of Pathology,

Mahatma Gandhi Medical College and Research Institute,

Puducherry.

E-mail: drvenkatraman1983@gmail.com

DOI: $10.14260 /$ jemds $/ 2016 / 1670$
2. Haematogenous spread from an internal lesion causing lupus vulgaris.

3. Direct extension into the skin from underlying tuberculous lymph node causing scrofuloderma.

The cell-mediated immune system is a major defense against the bacilli. The basic reaction of human tissue to tuberculous bacilli is a sequence, first of acute non-specific inflammation. But the neutrophils are unable to phagocytose and degrade the bacilli. Hence, the bacilli continues to multiply. Later when the macrophages phagocytose the organisms, tuberculous antigens induce the secretion of cytokines. Cytokines recruit and activate macrophages. Activated macrophages transform into epithelioid cells. Few of the epithelioid cells fuse to form Langhans giant cells. Caseation necrosis within the granuloma is seen as a consequence of delayed hypersensitivity reaction and is composed of dead macrophages and bacilli.

Lupus vulgaris is a form of secondary or reactivation tuberculosis caused due to haematogenous spread. Clinically, the lesions vary from single to a few, well-demarcated, reddish brown patches or deep seated nodules. These lesions are also referred as apple-jelly nodules. The disease is very chronic and slow with peripheral extensions of these lesions. Microscopic study shows a well-formed granuloma with caseous necrosis. Secondary changes in the epidermis are common. The 
epidermis may undergo atrophy and ulceration or it may become hyperplastic showing acanthosis, hyperkeratosis and papillomatosis. Margin of the ulcer may show pseudoepitheliomatous hyperplasia. Diagnosis may be missed if the biopsy is not deep enough. Longstanding tuberculous ulcer may undergo malignant transformation into squamous cell carcinoma. Tubercle bacilli are very few and hence can rarely be demonstrated by staining methods.

Scrofuloderma represents a direct extension into the skin from the underlying tuberculous infection, present most commonly in a lymph node or a bone. The lesion manifests as a blue-red, painless swelling that later ulcerates. Histopathological study from the lesion reveals an abscess or an ulcer in the upper dermis. Granulomas are seen in the deeper dermis.

Tuberculosis Verrucosa Cutis (TVC) represents an inoculated exogenous infection of the skin. The lesions in TVC are usually solitary and present as a verrucous plaque with an inflammatory borders and showing gradual peripheral extension. The verrucous surface exhibits fissures from which pus can be expressed. Most common sites include hands, knee, buttock and thighs.

Histopathological study reveals hyperkeratosis and acanthosis of the epidermis. Dermis shows acute inflammatory infiltrate with abscess, epithelioid granuloma and caseous necrosis. Papulonecrotic tuberculids are skin lesions in patients with tuberculosis. The most common sites of primary infection are lymph nodes. Acid-fast stain for acidfast bacilli are usually negative. These lesions are believed to be the result of immunologic reaction to a degenerated dead bacilli or fragment that have been deposited in the skin and subcutis. Clinically, these lesions manifests as erythematous papules over the limbs. They frequently ulcerate and heal leaving scars. On microscopy, these lesions show features of leukocytoclastic vasculitis. Granulomas are seen around the periphery of the lesions.

Cutaneous tuberculosis is frequently elusive as it mimics a wide differential diagnosis and also evades microbiological confirmation despite the availability of recent sophisticated techniques. In view of the increasing use of immunosuppressants and rise in HIV cases, 1 the present study is undertaken to evaluate the incidence, clinical profile and histopathological features of cutaneous TB.

\section{MATERIALS AND METHODS}

The present descriptive study included suspected and incidental cases, which were histopathologically diagnosed as cutaneous TB. The skin biopsies received in the Department of Pathology of Sri Manakula Vinayagar Medical College and Hospital were included in the study for a period of 1 year (July 2015 to June 2016). Skin biopsy was fixed in $10 \%$ formalin and the tissue bits were then processed through series of dehydration steps and embedded in wax blocks. Tissue sections of $5 \mu \mathrm{m}$ thicknesses were cut from paraffin embedded blocks and stained by conventional Haematoxylin and Eosin ( $\mathrm{H}$ and $\mathrm{E}$ ) stain and Ziehl-Neelsen stain for TB bacilli. Required patient details and clinical history for the study were retrieved from the biopsy requisition forms.

\section{RESULTS}

The current retrospective study was carried out for a period of 1 year (July 2015 to June 2016) in the Department of
Pathology, Sri Manakula Vinayagar Medical College and Hospital, Puducherry.

Of the 4800 biopsies received, 46 cases were diagnosed as Cutaneous Tuberculosis.

The incidence of Cutaneous Tuberculosis is $0.95 \%$. The study comprised of 25 males and 21 females.

Although, no age is immune to the disease, in the present study, age of the patient varied from 6 to 53 years. Majority (40\%) of the patients were between 21 - 30 years; $25 \%$ of the patients were between 31 - 40 years, $15 \%$ of the patients were between 11 - 20 years, $10 \%$ of the patients were between 41 50 years and $5 \%$ patients were between $0-10$ years and 51 60 years.

\begin{tabular}{|c|c|}
\hline Age (Years) & Percentage (\%) \\
\hline $0-10$ years & 5 \\
\hline $11-20$ years & 15 \\
\hline $21-30$ years & 40 \\
\hline $31-40$ years & 25 \\
\hline $41-50$ years & 10 \\
\hline $51-60$ years & 5 \\
\hline & Table 1 \\
\hline
\end{tabular}

Although, tuberculosis affects any site of the body, in the current study the commonest site affected was limb followed by head, neck and trunk.

\begin{tabular}{|c|c|}
\hline Site & Percentage (\%) \\
\hline Limb & 60 \\
\hline Head & 20 \\
\hline Neck & 15 \\
\hline Trunk & 5 \\
\hline \multicolumn{2}{|c|}{} \\
\hline
\end{tabular}

In the present study, lupus vulgaris was the most common variant of cutaneous TB followed by tuberculosis verrucosa cutis, scrofuloderma and papulonecrotic tuberculids (Table 3). Papulonecrotic tuberculids are uncommon lesions and arise in response to an internal focus of tuberculosis. Clinically, they present as hard, dusky-red papules which ulcerate or crust leaving pigmented atrophic scars over a period of time.

\begin{tabular}{|c|c|c|}
\hline Variant & $\begin{array}{c}\text { No. of } \\
\text { Cases }\end{array}$ & $\begin{array}{c}\text { Percentage } \\
\text { (\%) }\end{array}$ \\
\hline Lupus Vulgaris & 25 & 54 \\
\hline Scrofuloderma & 9 & 20 \\
\hline $\begin{array}{c}\text { Tuberculosis verrucosa } \\
\text { cutis }\end{array}$ & 9 & 20 \\
\hline $\begin{array}{c}\text { Papulonecrotic } \\
\text { tuberculids }\end{array}$ & 6 & 06 \\
\hline \multicolumn{2}{|c|}{ Table 3 } \\
\hline
\end{tabular}

Histopathological study showed granuloma composed of epithelioid cells, histiocytes, lymphocytes with or without Langhans type of giant cells and foreign body type of giant cells and caseous necrosis.

The commonest histopathological feature seen in the present study was a well formed granuloma, seen in $89 \%$ of the cases (Table 4). These granulomas were either seen in the upper dermis or in the deeper dermis. In cases of strong clinical 
suspicion where the granulomas were not visualised in the superficial sections, deeper sections were taken from the paraffin blocks for the study.

Associated and less commonly encountered histopathological features include epidermal hyperplasia, neutrophilic abscess, panniculitis and histiocytic aggregates.

\begin{tabular}{|c|c|c|}
\hline $\begin{array}{c}\text { Granuloma } \\
\text { Formation }\end{array}$ & $\begin{array}{c}\text { No. of Cases } \\
\text { (46) }\end{array}$ & $\begin{array}{c}\text { Percentage } \\
\text { (\%) }\end{array}$ \\
\hline Lupus vulgaris & 21 & 84 \\
\hline Scrofuloderma & 9 & 100 \\
\hline $\begin{array}{c}\text { Tuberculosis verrucosa } \\
\text { cutis }\end{array}$ & 8 & 89 \\
\hline $\begin{array}{c}\text { Papulonecrotic } \\
\text { tuberculids }\end{array}$ & 3 \\
\hline \multicolumn{2}{|c|}{ Table 4 } \\
\hline
\end{tabular}

Caseous necrosis was seen in 39\% of cases (Table 5); 11 (44\%) cases of Lupus Vulgaris, 4 (44\%) cases of scrofuloderma, 3 (33\%) cases of tuberculosis verrucosa cutis showed caseous necrosis. None of the cases of papulonecrotic tuberculids showed caseous necrosis. Ziehl-Neelsen stain for acid-fast bacilli showed positivity only in $7 \%$ of cases.

\begin{tabular}{|c|c|c|}
\hline $\begin{array}{c}\text { Caseous } \\
\text { Necrosis }\end{array}$ & $\begin{array}{c}\text { No. of Cases } \\
\text { (46) }\end{array}$ & $\begin{array}{c}\text { Percentage } \\
\text { (\%) }\end{array}$ \\
\hline Lupus vulgaris & 11 & 44 \\
\hline Scrofuloderma & 4 & 44 \\
\hline $\begin{array}{c}\text { Tuberculosis verrucosa } \\
\text { cutis }\end{array}$ & 3 & 33 \\
\hline $\begin{array}{c}\text { Papulonecrotic } \\
\text { tuberculids }\end{array}$ & 0 & 0 \\
\hline \multicolumn{2}{|c|}{ Table 5 } \\
\hline
\end{tabular}

\section{DISCUSSION}

Cutaneous tuberculosis although rare in Western Countries, yet frequently encountered in developing countries like India. Cutaneous TB accounts for $1.5 \%$ of all cases of extrapulmonary TB. ${ }^{3}$ In the present study, the incidence of extrapulmonary TB is high accounting for $0.95 \%$ in contrast to various other studies, in which the incidence ranged from $0.15 \%$ to $0.26 \% .4,5$

of the total number of 46 cases, there were 25 male patients (54\%) and 21 female patients (46\%) with slight male preponderance in comparison to other studies. ${ }^{4}$

Majority of the patients were in second and third decades of life, which was similar to other studies. The commonest site of involvement was limb similar to other studies carried out by Wong et $\mathrm{al}^{6}$ and Singh et al. ${ }^{7}$

The most common type of cutaneous TB was lupus vulgaris in comparison to the studies conducted by Acharya et $\mathrm{al}^{2}$ and Patra, ${ }^{1}$ while other studies showed Scrofuloderma as the commonest variant. 5,8

Lupus vulgaris commonly presents in immunocompetent patients. It occurs due to haematogenous, lymphatic or direct spread from tuberculosis elsewhere in the body.

Scrofuloderma represents a direct extension into the overlying skin from an underlying tuberculous focus, usually a lymph node but rarely an infected bone or joint. Cervical group of lymph nodes are affected frequently, although axillary, inguinal and other lymph nodes are also involved less commonly.
The well-formed epithelioid granulomas were observed in $84 \%$ of lupus vulgaris, all cases of scrofuloderma, and $89 \%$ cases of tuberculosis verrucosa cutis comparable to the studies conducted by Sehgal et al ${ }^{5}$ except for scrofuloderma where the author observed granuloma formation only in $39.1 \%$ cases.

Caseous necrosis was seen in $44 \%$ cases of lupus vulgaris in contrast to the study carried out by Gopinathan et al,10 where caseous necrosis was seen only in 8.3 cases.

\section{CONCLUSION}

Tuberculosis can virtually involve any organ system in the body. The incidence of pulmonary and extrapulmonary tuberculosis is on the rise, particularly in this HIV era. Cutaneous TB continues to be a health issue, especially among lower socioeconomic class. Although, the incidence of cutaneous TB is rare, it should be considered in patients presenting with atypical skin lesions.

Histopathologically, tuberculoid granulomas are close mimicker of other cutaneous granulomatous lesions like leprosy, fungal, parasitic infections and sarcoidosis.

Hence, elaborate clinical history with clinical presentation, skin biopsy with histopathological features and special staining method for identification of acid-fast bacilli are necessary to improve the efficiency in the early and accurate diagnosis of cutaneous TB.

Clinico-pathological correlation is essential in cases where clinical presentation poses diagnostic difficulties.

\section{REFERENCES}

1. Patra AC, Gharami RC, Banerjee PK. A profile of cutaneous tuberculosis. Indian J Dermatol 2006;51(2):105-7.

2. Acharya $\mathrm{KM}$, Ranpara $\mathrm{H}$, Dutta $\mathrm{R}$, et al. A clinicopathological study of 50 cases of cutaneous tuberculosis in Jamnagar district. Indian J Dermatol Venereol Leprol 1997;63(5):301-3.

3. Kumar B, Rai R, Kaur I, et al. Childhood cutaneous tuberculosis: a study over 25 years from northern India. Int J Dermatol 2001;40(1):26-32.

4. Kumar B, Kaur S. Pattern of cutaneous tuberculosis in North India. Indian J Dermatol Venereol Leprol 1986;52(4):203-7.

5. Sehgal VN, Srivastava G, Khurana VK, et al. An appraisal of epidemiologic, clinical, bacteriologic, histopathologic and immunologic parameters in cutaneous tuberculosis. Int J Dermatol 1987;26(8):521-6.

6. Wong KO, Lee KP, Chiu SF. Tuberculosis of the skin in Hong Kong. (A review of 160 cases). Br J Dermatol 1968;80(7):424-9.

7. Singh G. Lupus vulgaris in India. Indian J Dermatol Venereol Leprol 1974;40:257-60.

8. Gopinathan R, Pandit D, Joshi J, et al. Clinical and morphological variants of cutaneous tuberculosis and its relation to mycobacterium species. Indian J Med Microbiol 2001;19(4):193-6. 